\title{
Isolated limb infusion: Efficacy, toxicity and an evolution in the management of in-transit melanoma
}

\author{
Laura Chin-Lenn MBBS FRACS ${ }^{1}$, Claire Temple-Oberle MD FRCSC ${ }^{1,2}$, J Gregory McKinnon MD FRCSC ${ }^{1}$
}

\begin{abstract}
L Chin-Lenn, C Temple-Oberle, JG McKinnon. Isolated limb infusion: Efficacy, toxicity and an evolution in the management of in-transit melanoma. Plast Surg 2015;23(1):25-30.
\end{abstract}

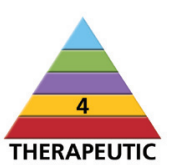

BACKGROUND: Isolated limb infusion (ILI) delivers low-flow chemotherapy via percutaneous catheters to treat melanoma in-transit metastases. OBJECTIVE: To describe the experience of two regional referral centres with ILI

METHODS: A retrospective review of patients who underwent ILI between 2002 and 2012 was performed. Outcomes were measured using the WHO criteria for response, the Wieberdink toxicity score and long-term limb function using the Toronto Extremity Salvage Score (TESS).

RESULTS: Fifty-two patients (mean age 66 years [range 27 to 90 years], female sex 65\%, and lower [treated] limb in 86\%) with 54 ILIs were reviewed. Wieberdink toxicity score was $\geq 3$ in 21 (39\%) procedures. Median follow-up was 18 months (range one to 117 months). Initial complete response (CR) was $29 \%$, partial response $27 \%$, stable disease $18 \%$ and progressive disease $27 \%$. Predictors of better initial response were low disease burden and previous treatment. One or more treatments after ILI were common (65\%). At 12 months, 19\% of ILI patients had died from melanoma but $44 \%$ of surviving patients experienced limb CR. At 24 months, 57\% of surviving patients experienced limb CR. The quality of life in the surviving, contactable patients according to the Toronto Extremity Salvage Score was 89\%.

CONCLUSION: Even if ILI does not result in CR for melanoma intransit metastases. it may slow disease progression as a single therapy, but more frequently in combination with other modalities.

Key Words: In-transit metastasis; Isolated limb infusion; Melanoma

\section{La perfusion d'un membre isolé : l'efficacité, la toxicité et une évolution de la prise en charge du mélanome en transit}

HISTORIQUE : La perfusion d'un membre isolé (PMI) libère une chimiothérapie à faible dose par des sondes percutanées afin de traiter les métastases en transit des mélanomes.

OBJECTIF : Décrire l'expérience de deux centres régionaux spécialisés à l'égard de la PMI.

MÉTHODOLOGIE : Les chercheurs ont réalisé une analyse rétrospective des patients qui ont subi une PMI entre 2002 et 2012. Ils ont mesuré les résultats à l'aide des critères de réponse de l'OMS, du score de toxicité de Wieberdink et de la fonction des membres à long terme selon le score de sauvetage des membres de Toronto (TESS).

RÉSULTATS : Les chercheurs ont analysé le cas de 52 patients (âge moyen de 66 ans [plage de 27 à 90 ans], $65 \%$ de femmes et jambe [traitée] dans $86 \%$ des cas) ayant eu 54 PMI. Dans 21 (39\%) des interventions, le score de toxicité de Wieberdink s'élevait à 3 ou plus. Le suivi médian était de 18 mois (plage de un à 117 mois). La réponse complète $(\mathrm{RC})$ initiale était de $29 \%$, la réponse partielle de $27 \%$, la stabilisation de $18 \%$ et l'évolution de $27 \%$. Un faible fardeau de la maladie et un traitement antérieur étaient les prédicteurs d'une meilleure réponse initiale. Il était courant d'administrer au moins un traitement après la PMI (65\%). Au bout de 12 mois, $19 \%$ des patients étaient décédés à cause du mélanome, mais $44 \%$ des survivants présentaient une RC du membre. Au bout de 24 mois, $57 \%$ des survivants présentaient une RC du membre. La qualité de vie des survivants non perdus au suivi s'établissait à 89 \% d'après le TESS.

CONCLUSION : Même si la PMI ne suscite pas une RC des métastases en transit des mélanomes, elle peut ralentir l'évolution de la maladie seule, mais surtout en association avec d'autres modalités.

long-term function, but this conflicts with our observation of the significant functional impairment that some patients experience $(18,19)$.

The present study describes our experience at the two initial institutions in Canada to use ILI (University of Calgary [Calgary, Alberta] and Western University [London, Ontario]) for disease outcomes, additional treatment modalities used and morbidity, including QoL using a reliable, validated tool in oncological limb surgery.

\section{METHODS}

Patients who underwent ILI between 2002 and 2012 were prospectively recorded. Retrospective chart review was undertaken to complete the data set and obtain follow-up. The present study was approved by the institutional ethics committee. Data included patient demographics, primary tumour characteristics, lymph node status, previous treatments and burden of ITM (quantified as low $[<10$ lesions, $<3 \mathrm{~cm}$ ] versus high) according to the combined Fraker and Rossi criteria $(1,3,20,21)$.

\section{ILI protocol}

The ILI protocol was similar to the Sydney Melanoma Unit protocol $(4,22)$. Chemotherapy doses were calculated from limb volumes measured using the water displacement technique or circumferential limb measurements $(6,11,23,24)$. Angiography catheters were inserted into 
TABLE 1 Summary of patient demographics, previous treatment,
primary tumour and in-transit melanoma (ITM)
characteristics and nodal status $(n=52)$

\begin{tabular}{|c|c|}
\hline Patient demographics & \\
\hline Age, years, mean (range) & $66(27-90)$ \\
\hline Male/female, $\mathrm{n} / \mathrm{n}$ & $18 / 34$ \\
\hline Any previous treatment & $41(78)$ \\
\hline Excision (may be multiple) & $32(62)$ \\
\hline Previous systemic therapy & $11(21)$ \\
\hline Interferon & 9 (4 for 1 year) \\
\hline Chemotherapy & 2 \\
\hline Unknown & 1 \\
\hline Previous radiation to treat ITM & $7(13)$ \\
\hline Unknown & 1 \\
\hline \multicolumn{2}{|l|}{ Previous other } \\
\hline Intralesional interleukin-2 & 3 \\
\hline Intradermal bacillus Calmette-Guérin & 1 \\
\hline Melacine vaccine & 1 \\
\hline Topical (cryotherapy/imiquimod) & 2 \\
\hline Isolated limb perfusion & 2 \\
\hline \multicolumn{2}{|l|}{ Primary tumour characteristics } \\
\hline Unknown primary & 4 \\
\hline Primary tumour characteristics available & 48 \\
\hline Breslow thickness, mm, mean (range) & $4.0(0.5-11)$ \\
\hline \multicolumn{2}{|l|}{ Clark level } \\
\hline 2 & 1 \\
\hline 3 & 5 \\
\hline 4 & 23 \\
\hline 5 & 8 \\
\hline Not recorded & 11 \\
\hline \multicolumn{2}{|l|}{ Location } \\
\hline Proximal arm & 2 \\
\hline Distal arm & 5 \\
\hline Proximal leg & 4 \\
\hline Distal leg & $37(77)$ \\
\hline \multicolumn{2}{|l|}{ ITM characteristics } \\
\hline Time from primary melanoma to development of ITM & $17(1-288)$ \\
\hline Time from ITM to ILI, months, mean (range) & $4(1-87)$ \\
\hline Dermal metastases & $23(45)$ \\
\hline Subcutaneous metastases & $30(56)$ \\
\hline \multicolumn{2}{|l|}{ Burden of disease } \\
\hline Low burden (<10 lesions, all <3 cm) & 18 \\
\hline High burden ( $\geq 10$ lesions, any $\geq 3 \mathrm{~cm}$ ) & 35 \\
\hline \multicolumn{2}{|l|}{ Nodal status at time of ILI } \\
\hline Nodal status unknown & 1 \\
\hline Nodal status known & 51 \\
\hline Clinically positive & 9 \\
\hline Clinically negative & 45 \\
\hline Sentinel node biopsy & 29 \\
\hline Sentinel node biopsy-positive, $\mathrm{n} / \mathrm{n}$ & $16 / 29$ \\
\hline Total with regional lymph node dissection, $\mathrm{n} / \mathrm{n}$ & $25 / 51$ \\
\hline
\end{tabular}

Data presented as $n$ or $n$ (\%) unless otherwise indicated. ILI Isolated limb infusion

the affected limb by an interventional radiologist ( 6 Fr for the artery, 8 Fr with multiple side-holes for the vein). Lower limb catheters were inserted via the contralateral groin and advanced to a position proximal to the knee. Upper limb catheters were inserted via the groin into the brachial artery and basilic vein. Subcutaneous heparin was administered and the patient was warmed throughout the radiology procedure.
Patients received general anesthesia in the operating room and intravenous systemic heparin (10,000 IU) was infused. The patient was warmed (blankets, a heated air blanket beneath the limb and an overhead heat lamp above) to a target limb temperature of $37^{\circ} \mathrm{C}$. Selected patients with symptomatic lesions were resected before infusion. Skin and muscle temperature probes were monitored continuously, aiming for an eventual temperature of $38.5^{\circ} \mathrm{C}$. Line patency was verified and papaverine administered into the limb via the arterial catheter. Blood was withdrawn and injected into the isolated limb through a blood warmer to raise the limb temperature. A proximal pneumatic tourniquet was applied, or in cases in which the disease extended more proximally, a Steinmann pin is inserted into the iliac crest and an Esmarch bandage used as a proximal tourniquet. Unaffected distal extremities were excluded with an Esmarch bandage. The chemotherapy (melphalan $7.5 \mathrm{~mL} / \mathrm{L}$ of tissue to be infused with or without actinomycin D $75 \mu \mathrm{g} / \mathrm{L}$ without adjustment for ideal body weight) was diluted in $400 \mathrm{~mL}$ of prewarmed saline and infused into the limb via the arterial catheter through a heating coil. After chemotherapy infusion, the distal tourniquet was removed and the limb was flushed with room temperature fluid until the return was clear. When $800 \mathrm{~mL}$ to $1000 \mathrm{~mL}$ of fluid had been removed, the proximal tourniquet was released. Protamine was administered and the catheters removed following confirmation of heparin reversal.

Postoperatively, patients were prescribed antiemetics and bed rest for $24 \mathrm{~h}$ with the treated limb elevated. The limb was monitored clinically for compartment syndrome and biochemically with daily creatinine kinase levels. Steroids were administered if the creatinine kinase level increased to $>1000 \mathrm{U} / \mathrm{L}$. Selected patients received postoperative therapeutic anticoagulation (heparin followed by warfarin).

\section{Assessment of complications and response}

Complications were recorded including the Wieberdink limb toxicity score (6). WHO criteria of response assessment was based on two observations taken $>4$ weeks apart and defines CR as the disappearance of all measurable disease; partial response (PR) as $>50 \%$ decrease in total tumour size and no appearance of new lesions or progression of any lesion; stable disease as no change or $<50 \%$ decrease in tumour size; and progressive disease (PD) as any increase in size (13).

\section{Functional outcome}

Patients were contacted by telephone to administer a questionnaire (Toronto Extremity Salvage Score [TESS]) (14). This is a validated scoring system for patients treated for limb extremity sarcomas. Thirty functional aspects of the treated limb (eg, putting on a pair of pants, carrying a shopping bag or briefcase, getting into and out of a car) are rated on a Likert scale of 1 (impossible to do) to 5 (not at all difficult) and applicable answers calculated. Two additional questions summarize the patient's perception of overall performance and level of disability.

\section{Statistical analysis}

Statistical analysis was performed using STATA (www.stata.com). Fisher's exact test and $\chi^{2}$ test were used to compare categorical variables. Outcomes were based on time from the initial ILI procedure. The Kaplan-Meier method and log-rank test were used to analyze factors associated with melanoma-specific survival.

\section{RESULTS}

Fifty-four ILIs were performed on 52 patients. Patient demographics, previous treatments and tumour characteristics are summarized (Table 1). All patients had negative staging with computed tomography, except one patient who declined staging. Limb volumes were measured using water-displacement technique $(n=31)$, limb circumference measurements with volume calculation $(n=21)$ or volume estimation due to failed water-displacement technique $(n=2)$. Melphalan $(7.5 \mathrm{~mL} / \mathrm{L}$ of tissue to be infused) with or without actinomycin-D $(75 \mu \mathrm{g} / \mathrm{L})$ without adjustment for ideal body weight were used. The agents and circulating times varied according to the surgeons' experience. Both agents were infused for $30 \mathrm{~min}$ (nine 
TABLE 2

Wieberdink toxicity score ( $n=54$ procedures)

\begin{tabular}{llc}
\hline Grade & Effect & n (\%) \\
\hline 1 & No visible effect & $4(7)$ \\
2 & Slight erythema and/or edema & $29(54)$ \\
3 & Considerable erythema and/or edema with & $14(26)$ \\
& blistering & $7(13)$ \\
4 & Extensive epidermolysis and/or obvious & \\
& damage to deep tissues with a threatened & \\
& or actual compartment syndrome & $0(0)$ \\
\hline
\end{tabular}

TABLE 3

Additional therapies following isolated limb infusion procedures*

\begin{tabular}{lc}
\hline Treatment & 2 \\
\hline Unknown & 17 \\
None & 13 \\
Resection & 12 \\
Systemic & 2 \\
$\quad$ Interferon & 6 \\
Dacarbazine & 3 \\
Ipilimumab & 3 \\
Chemotherapy & 6 \\
Radiation & 2 \\
Palliative amputation & 6 \\
Intralesional interleukin-2 & 2 \\
Imiquimod & 2 \\
Dendritic cell vaccine & 1 \\
Repeat isolated limb infusion & 2
\end{tabular}

Data presented as $n$. *May be multiple per patient

procedures) and single-agent melphalan for $15 \mathrm{~min}$ (20 procedures) or $30 \mathrm{~min}(\mathrm{n}=25)$. A Steinmann pin and Esmarch tourniquet were used in four patients. Large or symptomatic (eg, ulcerated) lesions were excised perioperatively in five procedures. Median hospital stay was seven days (range three to 37 days). Follow-up time was median 18 and mean 25 months (range one to 111 months).

Wieberdink toxicity is summarized in Table 2. Two patients required fasciotomy. No patients required amputation (grade 5). Other limb complications were deep vein thrombosis (DVT) in three patients following discharge from hospital.

\section{Initial response predictors}

At three months, five patients were lost to follow-up. Of the remaining patients, 14 had CR (30\%), 13 PR (26\%), nine stable disease (17\%) and 13 PD (28\%). As expected, on univariate analysis, low burden of disease significantly predicted initial response of CR and high burden of disease more likely to predict $\mathrm{PD}(\mathrm{P}=0.01)$. The administration of any previous therapy before ILI significantly predicted better response $(\mathrm{P}=0.05)$. On univariate analysis, initial response was not significantly associated with sex $(P=0.74)$, age $>70$ years $(P=0.81)$, limb treated $(\mathrm{P}=0.22)$, dermal vs subcutaneous lesions $(\mathrm{P}=0.60)$, time to development of ITM $>18$ months $(\mathrm{P}=0.37)$, time from development of ITM to time of ILI $>6$ months $(\mathrm{P}=0.25)$ or Wieberdink toxicity $(\mathrm{P}=0.27)$.

\section{Overall survival predictors}

Melanoma-specific survival at 12 months was $77 \%$, at 24 months $57 \%$ and at 60 months $43 \%$ (Figure 1A).

Initial response was measured at one month using WHO criteria. Although Figure 1B demonstrates a visual trend toward poorer initial response to ILI decreasing melanoma-specific survival, the difference by log-rank was not significant $(\mathrm{P}=0.32)$. Initial response was not significantly associated with sex $(P=0.13)$, age $>70(P=0.32)$, time to ILI $>6$ months $(\mathrm{P}=0.91)$, time to development of ITM $>18$ months

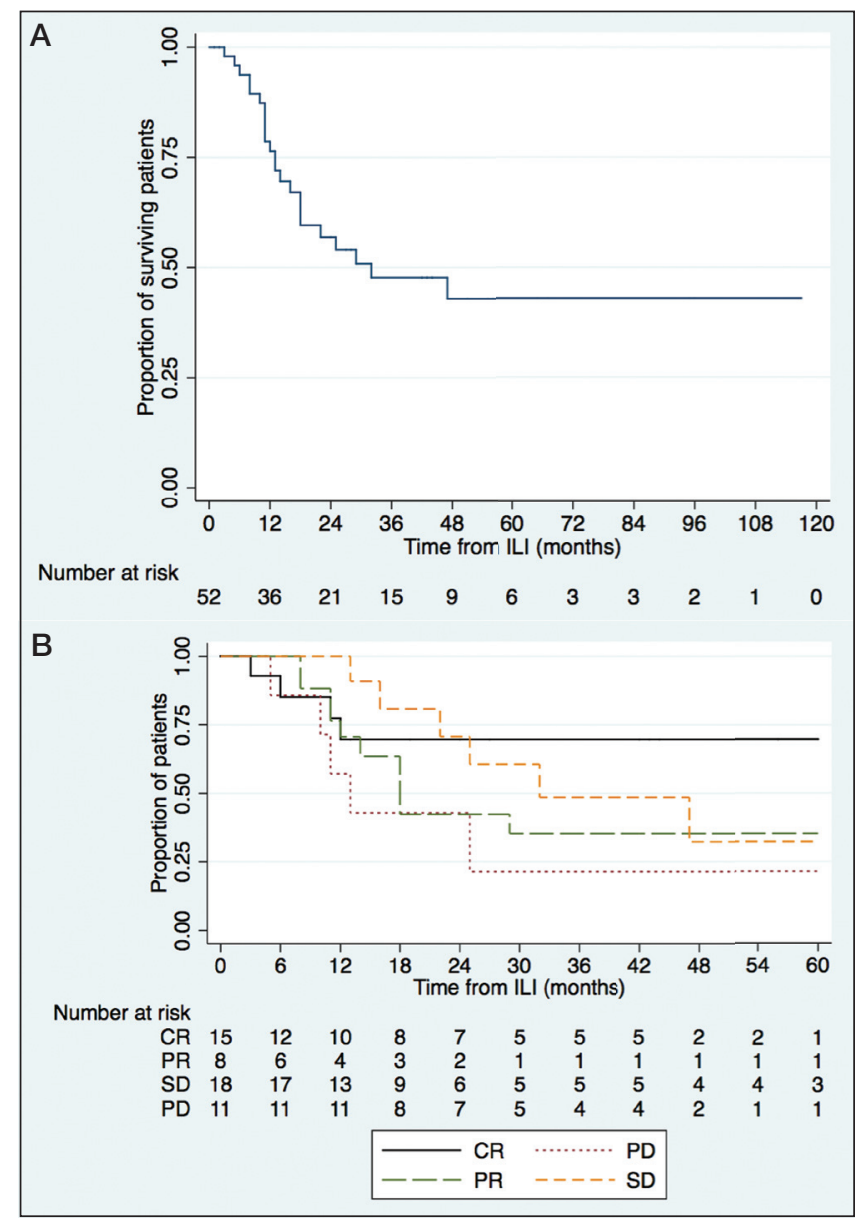

Figure 1) A Melanoma-specific survival for all patients treated with isolated limb infusion (ILI). B Melanoma-specific survival according to initial response to ILI (log-rank 0.35). CR Complete response; PD Progressive disease; PR Partial response; SD Stable disease

\section{TABLE 4}

Limb in-transit melanoma (ITM) status following initial isolated limb infusion (ILI) $(n=52)$

\begin{tabular}{lcccc}
\hline & \multicolumn{5}{c}{ Months } \\
\cline { 2 - 5 } Patient status & $\mathbf{3}$ & $\mathbf{6}$ & $\mathbf{1 2}$ & $\mathbf{2 4}$ \\
\hline Procedures, $\mathrm{n}$ & 47 & 43 & 34 & 21 \\
Free of ITM & $14(30)$ & $18(42)$ & $15(44)$ & $12(57)$ \\
Partial response & $12(26)$ & $3(7)$ & 2 & 0 \\
Stable disease & $8(17)$ & $6(14)$ & 3 & 2 \\
Progressive disease & $13(28)$ & $16(37)$ & $15(44)$ & 7 \\
Died of melanoma, $\mathrm{n}$ & 0 & 2 & 10 & 19 \\
Lost to follow-up/died of & 5 & 7 & 8 & 12 \\
\multicolumn{1}{c}{ other causes/repeat ILI, $\mathrm{n}$} & & & & \\
\hline
\end{tabular}

Data presented as $n$ (\%) unless otherwise indicated

( $\mathrm{P}=0.53)$, burden of disease $(\mathrm{P}=0.61)$, nodal status $(\mathrm{P}=0.34)$, dermal versus subcutaneous lesions $(\mathrm{P}=0.55)$ and Wieberdink toxicity $(\mathrm{P}=0.86)$ did not significantly predict survival.

Following ILI, 35 patients had one or more additional therapies for ITM (Table 3). The eventual limb fate following ILI and other treatments are outlined (Table 4). Control of the disease in the limb was obtained in 12 patients at 24 months (57\% of survivors). Of these, only two were treated with ILI alone, with the others having additional intralesional interleukin-2 $(n=3)$, resection $(n=2)$, radiation and systemic therapy $(n=1)$, resection and topical imiquimod $(n=1)$, resection and radiation $(n=1)$, radiation alone $(n=1)$ and ipilimumab $(n=1)$. 
TABLE 5

Long-term follow-up of isolated limb infusion (ILI) patients using the Toronto Extremity Salvage Score (TESS) questionnaire

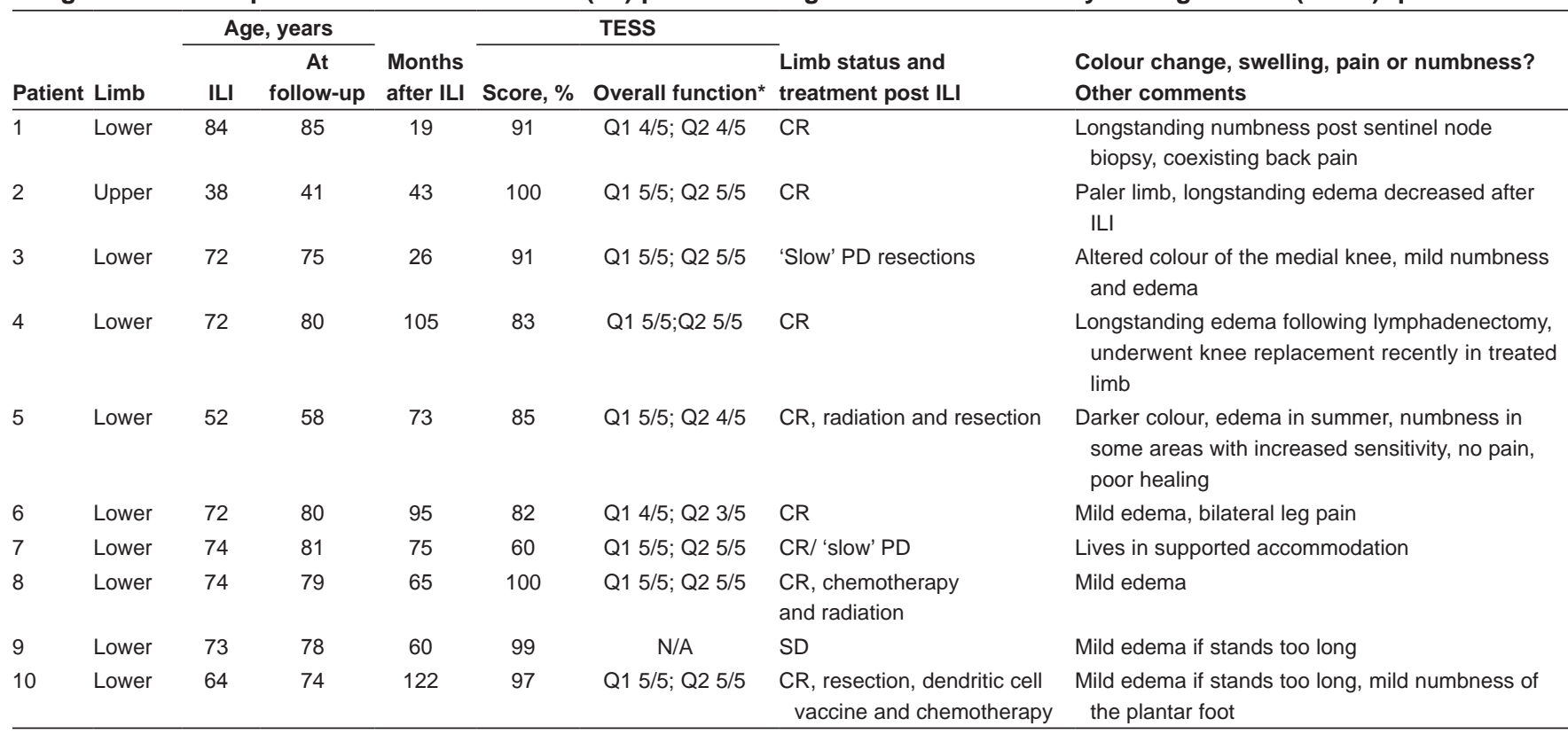

*Two questions: question 1 (Q1) - self-rating of ability to perform usual activities (1: impossible to perform to 5: not at all difficult); question 2 (Q2) - self-rating of disability (1: completely disabled to 5: not at all disabled). CR Complete response; N/A Not applicable; PD Progressive disease; SD Stable disease

QoL outcomes

At the time of telephone contact to administer the questionnaire, 31 patients were confirmed to be deceased and one patient was in highlevel care and unable to communicate. Of the remaining 21 patients, 10 were contactable. Table 5 details the individual TESS scores, limb status and chronic issues. The mean age at time of the questionnaire was 73 years (median 78.5 years) and time post-ILI was 68 months (range 19 to 122 months). TESS ranged from 60\% to 100\% (median $91 \%$ ). Some patients mentioned their associated comorbidities and age-related decreased functional status. As a baseline, in an otherwise healthy population TESS demonstrates an age-related decline, with scores of $98 \%$ in people in their 30 s and $76 \%$ to $88 \%$ for those in their 70s (18). The most common physical complaint in our patients was mild edema, especially after prolonged standing. Our patients noted that additional procedures (eg, regional lymphadenectomy or radiation) sometimes led to numbness and edema, making true ILIassociated morbidity difficult to determine. The lowest TESS was $60 \%$ (patient 7, 81 years of age). She lived in supported accommodation and found only 15 of 30 questions applicable. Surprisingly, she rated her overall ability to perform her activities as "not at all difficult" ( 5 of 5) and considered herself to be "not at all disabled" (5 of 5). Conversely, patient 5 ( 58 years of age) who had subsequent radiation and resection and attributed her CR to these treatments, expressed high dissatisfaction with the ILI but had a TESS of $85 \%$ and rated her overall disability as "mildly disabled" (4 of 5).

\section{DISCUSSION}

ILI is now a widely accepted procedure for the treatment of ITM. It has been suggested that, despite lower response rates compared with HILP, ILI should be attempted initially due to lower morbidity, with HILP reserved for repeated procedures $(20,21)$. However, the role of ILI is being redefined with the development and implementation of other systemic and local therapies.

\section{Review of own progress}

Increased experience in performing ILI improves outcomes (22). We have continually re-evaluated our outcomes and complications. For example, chemotherapy was changed from melphalan with actinomycin-D to melphalan alone based on lack of evidence for the additional actinomycin-D, and infusion time reduced from $30 \mathrm{~min}$ to $15 \mathrm{~min}$ based on early complications. Significant toxicity was noted around the knee, possibly due to an arterial 'streaming effect' of the chemotherapy. Subsequent patients had their knee wrapped with an Esmarch bandage for the first $10 \mathrm{~min}$ of the infusion to reduce chemotherapy delivery and complications. Postoperative therapeutic anticoagulation was instituted after two patients developed DVTs. DVT rates of $4 \%$ to $14 \%$ following ILI have been described in other series $(11,23,24)$. Postoperative steroids were used selectively on the basis of Wieberdink toxicity and/or elevated creatine kinase.

Response classification and comparison with other series The Response Evaluation Criteria in Solid Tumours (RECIST) criteria are the current guidelines for measuring disease response to treatment, but it is difficult to classify ITM due to its heterogenous size and distribution (25). The WHO criteria are older but have been used more frequently in other series of ILI and facilitate comparison to those series.

Regardless of the criteria used, there are inherent difficulties with response classification following ILI, possibly contributing to the variability of results among ILI series. Response criteria cannot be applied if visible disease is resected at time of ILI. Similarly, ITM may regress pathologically but leave pigmented lesions either similar in size to pretreatment or not diminished significantly enough to qualify as a CR or PR. Biopsies of residual lesions can confirm response but may not be preferred by the clinician or patient for response classification reasons alone. Furthermore, patients often have many lesions, of which only a few would undergo biopsy.

Our response rate is similar to other series with CR 23\% to $38 \%$ and PR $14 \%$ to $47 \%(15-17,26)$. Response to ILI has been shown in other series to be associated with overall survival but, in our series, was not statistically significant (26).

\section{Meaning of response}

Despite negative radiological staging before ILI, at least one-third of our patients experienced melanoma-related death within two years. Bearing this in mind, while CR may be the benchmark of success, ILI could be regarded as a palliative procedure to control limb disease. In our series, $55 \%$ surviving patients were free of ITM at two years. 
Although eventual limb outcomes may be credited to subsequent treatment modalities, ILI may possibly have contributed due to its role in micrometastatic disease, even for patients who do not experience an initial CR. We have demonstrated that, at least initially, low burden of disease predicts better response. It is unclear whether the long-term durable responses with or without other treatments are due to slowing of the disease progression from ILI or from biologically less aggressive disease.

A minority of patients will attain a CR. A majority will attain control of disease in their limb with a combination of therapies. Clearly, ILI is an effective treatment but has significant cost and morbidity. Now that other effective treatments for in-transit disease have been developed it is doubtful whether ILI should be the first line of therapy after failed resection. It is more likely to be a second- or thirdline treatment after intralesional or systemic therapy has failed. However, it is encouraging that with multiple effective therapies at hand, many of these patients will attain control of melanoma in the limb and long-term disease free survival.

\section{Complications and QoL}

Our toxicity of Wieberdink score $\geq 3$ in $39 \%$ of cases is comparable with the literature at $10 \%$ to $42 \%(15-17,26)$.

Although short-term complications of ILI are well documented, QOL outcomes have not been well studied. McClaine et al (19) developed a survey that retrospectively assessed limb function preoperatively, one week and three months postoperatively, and time of last follow-up (19). The most common symptoms were limb edema $(82 \%)$, numbness $(65 \%)$ and stiffness $(35 \%)$. This study highlighted that while ILI may have durable CR ( $41 \%$ at 19.4 months), significant long-term morbidity may occur. However, they conclude that there is no long-term residual functional impairment. In our study, we did not perform baseline TESS. All of our contactable patients except one were pleased with their limb function overall. However, this was a strongly biased population of surviving patients living at home, and excluded patients in a care facility who may have potentially experienced more significant toxicities from ILI.

\section{REFERENCES}

1. Fraker DL, Alexander HR, Andrich M, Rosenberg SA. Treatment of patients with melanoma of the extremity using hyperthermic isolated limb perfusion with melphalan, tumor necrosis factor, and interferon gamma: Results of a tumor necrosis factor dose-escalation study. J Clin Oncol 1996;14:479-89.

2. Edge SB, Byrd DR, Compton CC, editors. AJCC Cancer Staging Manual, 7th edn. New York: Springer; 2010.

3. Rossi CR, Foletto M, Pilati P, Mocellin S, Lise M. Isolated limb perfusion in locally advanced cutaneous melanoma. Semin Oncol 2002;29:400-9.

4. Thompson JF, Kam PC, Waugh RC, Harman CR. Isolated limb infusion with cytotoxic agents: A simple alternative to isolated limb perfusion. Semin Surg Oncol 1998;14:238-47.

5. Jaques DP, Coit DG, Brennan MF. Major amputation for advanced malignant melanoma. Surg Gynecol Obstet 1989;169:1-6.

6. Wieberdink J, Benckhuysen C, Braat RP, van Slooten EA, Olthuis GA. Dosimetry in isolation perfusion of the limbs by assessment of perfused tissue volume and grading of toxic tissue reactions. Eur J Cancer Clin Oncol 1982;18:905-10.

7. Grotz TE, Mansfield AS, Kottschade LA, et al. In-transit melanoma: An individualized approach. Oncology 2011;25:1340-8.

8. Kidner TB, Morton DL, Lee DJ, et al. Combined intralesional Bacille Calmette-Guérin (BCG) and topical imiquimod for in-transit melanoma. J Immunother 2012;35:716-20.

9. Boyd KU, Wehrli BM, Temple CLF. Intra-lesional interleukin-2 for the treatment of in-transit melanoma. J Surg Oncol 2011;104:711-7.

10. Seegenschmiedt MH, Keilholz L, Altendorf-Hofmann A, et al. Palliative radiotherapy for recurrent and metastatic malignant melanoma: Prognostic factors for tumor response and long-term outcome: A 20-year experience. Int J Radiat Oncol Biol Phys 1999;44:607-18.

11. Raymond AK, Beasley GM, Broadwater G, et al. Current trends in regional therapy for melanoma: Lessons learned from 225 regional

\section{Modern role of ILI}

Our use of ILI has decreased in recent years. Our current algorithm to treat ITM begins with resection. If surgery is unsuccessful or not feasible, then intralesional interleukin-2 is used. This treatment has an overall response rate of $82 \%$ (CR $51 \%$ and PR 31\%) with relatively simple regime and low toxicity (9). If this treatment fails, ILI is the next line of defence. If all of these treatments fail, systemic therapy is used. Any successful treatment can be repeated, including ILI. The early use of the new systemic agents for ITM in the absence of stage IV disease is undefined at present.

\section{Limitations}

The present study has described the outcomes, complications and long-term function of ILI for melanoma ITM. However, it was a retrospective series and technical data (eg, intraoperative limb temperatures, postoperative creatine kinase) were not always available. Long-term follow-up is often with local physicians due to the long distances travelled to access this treatment. The TESS was performed in a biased patient population who were alive long after ILI and functioning well enough to be at home.

\section{CONCLUSIONS}

ILI can be an effective treatment of melanoma ITM but is frequently used in combination with other treatments. The current role of ILI given the availability of new local injection treatments and systemic agents remains to be defined. For patients who do not succumb to systemic disease and experience a durable response to treatment, longterm limb morbidity measured by a validated tool is acceptable.

DISCLOSURES: The authors have no financial disclosures or conflicts of interest to declare. chemotherapy treatments between 1995 and 2010 at a single institution. ACS Elsevier Inc 2011;213:306-16.

12. Thompson JF, Hunt JA, Shannon KF, Kam PC. Frequency and duration of remission after isolated limb perfusion for melanoma. Arch Surg 1997;132:903-7.

13. Lindnér P, Doubrovsky A, Kam PC, Thompson JF. Prognostic factors after isolated limb infusion with cytotoxic agents for melanoma. Ann Surg Oncol 2002;9:127-36.

14. Davis AM, Wright JG, Williams JI, Bombardier C, Griffin A, Bell RS. Development of a measure of physical function for patients with bone and soft tissue sarcoma. Qual Life Res 1996;5:508-16.

15. Beasley GM, Caudle A, Petersen RP, et al. A multi-institutional experience of isolated limb infusion: Defining response and toxicity in the US. Am Coll Surg 2009;208:706-15.

16. Beasley GM, Petersen RP, Yoo J, et al. Isolated limb infusion for in-transit malignant melanoma of the extremity: A well-tolerated but less effective alternative to hyperthermic isolated limb perfusion. Ann Surg Oncol 2008;15:2195-205.

17. Barbour AP, Thomas J, Suffolk J, Beller E, Smithers BM. Isolated limb infusion for malignant melanoma: Predictors of response and outcome. Ann Surg Oncol 2009;16:3463-72.

18. Clayer M, Doyle S, Sangha N, Grimer R. The Toronto extremity salvage score in inoperated controls: An age, gender, and country comparison. Sarcoma 2012;2012:1-5.

19. McClaine RJ, Giglia JS, Ahmad SA, McCoy SJ, Sussman JJ. Quality of life outcomes after isolated limb infusion. Ann Surg Oncol 2012;19:1373-8.

20. Chai CY, Deneve JL, Beasley GM, et al. A multi-institutional experience of repeat regional chemotherapy for recurrent melanoma of extremities. Ann Surg Oncol 2011;19:1637-43.

21. Turley RS, Raymond AK, Tyler DS. Regional treatment strategies for in-transit melanoma metastasis. Surg Oncol Clin N Am 2011;20:79-103. 


\section{Chin-Lenn et al}

22. Huismans AM, Kroon HM, Kam PCA, Thompson JF. Does increased experience with isolated limb infusion for advanced limb melanoma influence outcome? A comparison of two treatment periods at a single institution. Ann Surg Oncol 2011;18:1877-83.

23. Mian R, Henderson MA, Speakman D, Finkelde D, Ainslie J, McKenzie A. Isolated limb infusion for melanoma: A simple alternative to isolated limb perfusion. Can J Surg 2001;44:189-92.

24. Vohra NA, Turaga KK, Gonzalez RJ, et al. The use of isolated limb infusion in limb threatening extremity sarcomas. Int J Hyperthermia 2013;29:1-7.
25. Eisenhauer EA, Therasse P, Bogaerts J, et al. New response evaluation criteria in solid tumours: Revised RECIST guideline (version 1.1). Eur J Cancer 2009;45:228-47.

26. Kroon HM, Moncrieff M, Kam PCA, Thompson JF. Outcomes following isolated limb infusion for melanoma. A 14-year experience. Ann Surg Oncol 2008;15:3003-13. 